\title{
Improving ECE Education in Sub-Saharan African Countries Using the Mo- bile Studio Technology and Pedagogy
}

\section{Dr. Yacob Astatke, Morgan State University}

Dr. Yacob Astatke completed both his Doctor of Engineering and B.S.E.E. degrees from Morgan State University (MSU) and his M.S.E.E. from Johns Hopkins University. He has been a full time faculty member in the Electrical and Computer Engineering (ECE) department at MSU since August 1994 and currently serves as the Associate Chair for Undergraduate Studies. Dr. Astatke is the winner of the 20122013 American Society for Engineering Education (ASEE) Mid-Atlantic Region Distinguished Teacher Award. He teaches courses in both analog and digital electronic circuit design and instrumentation, with a focus on wireless communication. He has more than 15 years experience in the development and delivery of synchronous and asynchronous web-based course supplements for electrical engineering courses. He has published over 35 papers and presented his research work at regional, national and international conferences. He also runs several exciting summer camps geared towards middle school, high school, and community college students to expose and increase their interest in pursuing Science Technology Engineering and Mathematics (STEM) fields. Dr. Astatke travels to Ethiopia every summer to provide training and guest lectures related to the use of the mobile laboratory technology and pedagogy to enhance the ECE curriculum at five different universities.

\section{Dr. Craig J. Scott, Morgan State University \\ Dr. Jumoke Oluwakemi Ladeji-Osias, Morgan State University}

Dr. Jumoke Ladeji-Osias is Associate Professor and Associate Chair for Graduate Studies in the Department of Electrical and Computer Engineering at Morgan State University. She earned in B.S. in electrical engineering from the University of Maryland, College Park and a Ph.D. in biomedical engineering from Rutgers, The State University of New Jersey. She coordinates the departmental graduate program and teaches both undergraduate and graduate courses in computer engineering, primarily in designing digital systems for hardware. She is the PI for Scholars in Engineering (SiE), an NSF S-STEMS scholarship for undergraduate and Master's students. She is a member of the Morgan team that is developing online laboratory courses for undergraduate students. Her research expertise is in algorithm optimization for FPGA implementation and her research group has developed a novel biologically inspired image fusion algorithm. She has over 35 journal and conference publications combined.

\section{Prof. Kenneth A Connor, Rensselaer Polytechnic Institute}

Kenneth Connor is a professor in the Department of Electrical, Computer, and Systems Engineering, where he teaches courses on plasma physics, electromagnetics, electronics and instrumentation, electric power, and general engineering. His research involves plasma physics, electromagnetics, photonics, engineering education, diversity in the engineering workforce, and technology enhanced learning. Since joining the Rensselaer faculty in 1974, he has been continuously involved in research programs at such places as Oak Ridge National Laboratory and the Universities of Texas and Wisconsin in the U.S., Kyoto and Nagoya Universities in Japan, the Ioffe Institute in Russia, and Kharkov Institute of Physics and Technology in Ukraine. He was ECSE Department Head from 2001-2008 and served on the board of the ECE Department Heads Association from 2003-2008. He is presently the Education Director for the SMART LIGHTING NSF ERC.

\section{Mr. Salessawi Ferede Yitbarek, Addis Ababa University, Institute of Technology \\ Mr. Albert Edward Sweets Jr., iSTEMS \\ Dr. Farzad Moazzami, Morgan State University}

Dr. Farzad Moazzami completed both his Doctor of Engineering (2011) and M.Eng (2009) degrees from Morgan State University (MSU) and his B.S.E.E. from Azad University of Tabriz in Iran. He has been a full time faculty member in the Electrical and Computer Engineering (ECE) department at MSU since 
September 2011. He is experienced in the development and delivery of hybrid and online electrical engineering courses. Dr. Farzad Moazzami currently oversees activities of WiNetS lab in Morgan State University and works with undergrad and graduate students on cyber security, RF communications and digital signal processing topics under various research programs. 


\title{
Improving ECE Education in developing Sub-Saharan African Countries Using the Mobile Studio Technology and Pedagogy
}

\begin{abstract}
In today's global and highly competitive world, human capital has been so important that finding, developing, and retaining highly qualified workers, that can function in high demand and high growth sectors such as Science Technology Engineering and Mathematics (STEM) is very critical. The higher education sector of Africa has been decimated by the lack of funding and shortage of qualified instructors [1]. The shortage is magnified in STEM areas that require advanced training for the instructors and expensive equipment to conduct the hands-on laboratories. The lack of dependable laboratory equipment, especially in engineering education, has led higher education institutions in developing nations to focus more on the theoretical aspect of STEM education as compared to the practical applications. A possible solution to the problem is to develop collaborations with higher education institutions in the developed nations to provide targeted training on new pedagogy and state of the art mobile laboratory technology that will allow universities in Africa to teach STEM subjects with hands-on activities at a fraction of the cost of the regular equipment.

This paper will discuss the results of an on-going three year collaboration between the Electrical and Computer Engineering (ECE) departments of and two universities in Ethiopia,

(AAiT) and the

(iOTech-HU). The collaboration was based on the implementation of the Mobile Studio IOBoard ${ }^{\mathrm{TM}}$ (MS-IOBoard), which is a small, inexpensive hardware platform for use in a home, classroom or remote environment. When coupled with the Mobile Studio Desktop ${ }^{\mathrm{TM}}$ software, the system duplicates a large amount of the hardware valued at thousands of dollars. The project's major goal was to enable hands-on exploration of ECE principles, devices, and systems that have historically been restricted to expensive laboratory facilities that are not readily available in most engineering schools in developing countries. The results of the collaborations have so far been very promising. The students enrolled in the ECE programs at AAiT and iOTECH-HU have been able to use the new mobile instrumentation and pedagogy to work on new laboratory experiments and advanced projects. If successful, this approach can serve as a model of efficient and cost-effective collaboration between engineering schools in the USA and Africa that can be used to improve ECE education in developing countries.
\end{abstract}

\section{Introduction}

Although several approaches have been used during the past 20 years to reverse the brain drain, the current state of higher education in Africa still shows that there is a significant shortage of qualified scientists and educators with advanced degrees. A recent report from the 
International Organization for Migration (IOM) [1] indicates that Africa has been losing 20,000 professionals per year since 1990, and that close to 300,000 African professionals currently reside outside their home continent. The same report indicated that Ethiopia lost $75 \%$ of its skilled workforce between 1980 and 1991. These facts prompted a leader from the United Nations (UN) Economic Commission for Africa (ECA) to say, "In 25 years, Africa will be empty of brains [2]".

Developing nations, especially those located in Sub-Saharan Africa have realized that higher education (also known as tertiary education) is critical for their future economic development. A 2006 report compiled by United Nations Educational Scientific and Cultural Organization (UNESCO) indicates that several African nations have launched large expansions of their private and public higher education sector [3]. One country that has taken a giant leap in expanding its tertiary education sector is Ethiopia. Over the past five years, the University Capacity Building Program (UCBP) has undertaken a large-scale capacity development and construction project of 13 universities at 15 different sites throughout Ethiopia, mostly in rural locations (see Fig.1). The project was developed and funded by the Ethiopian Ministry of Education (MOE). The project aims to geographically decentralize and expand the country's higher education system and create equitable access to tertiary education throughout the country by increasing the number of students who live and study on UCBP campuses from around 90,000 in 2010 to around 125,000 when the project is completed[4]. Both the MOE and UCBP hope that the students graduating from the new universities "will form the backbone of a qualified and adaptable human resource base that will drive Ethiopia's development forward." The vision of the MOE also indicates that the new universities "will strengthen secondary education and Technical and Vocational Education and Training (TVET) by focusing on training qualified teachers.”

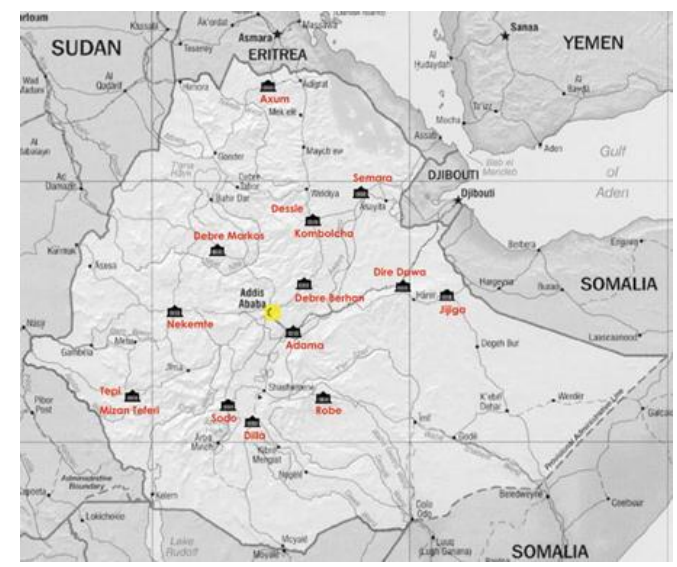

Figure 1: Planned thirteen new university constructions in Ethiopia (source[4])

The final goals of this ambitious and transformative project will not be fully accomplished unless the MOE and UCBP undertake a similar approach to train the next generation qualified and well trained university teachers that will fill the posts in the new 
universities under construction. Finding qualified and properly trained university teachers is hard in any subject area. The task is even harder in advanced and high demand areas such as STEM because they require additional laboratories and specialized equipment that are very expensive to purchase and maintain in order to teach and properly train the students with practical hands-on exercises. The impact of STEM education is also minimized and sometimes compromised when the ratio between the available equipment and the number of students becomes high. The solution to such a problem is to either decrease the studio/laboratory equipment ratio, or increase the availability of laboratory equipment. Although achieving both goals seems unattainable, the development and availability of state of the art teaching/training laboratory equipment has started making this vision a reality.

The Ethiopian government has laid out a five year strategic plan for all higher education institutions that requires a share of $40 \%$ of the first year students to be enrolled in the various engineering majors. (iOTech-HU) has seen a tremendous growth in the enrollment of its students since its start in 2003. Presently the iOTechHU has over 4,500 students in its seven programs. The ECE department currently has around 1100 students who are enrolled in second to fourth year courses that require the use of the laboratory equipment such as the MS-IOBoard. The department usually accepts between 100 and 150 first year student every year. AAiT has also seen a tremendous growth in the enrollment during the past five years. Presently, AAiT has over 10,000 students in its undergraduate and graduate programs. The ECE department currently has around 1000 students who are enrolled in second to fourth year courses that require the use of the laboratory equipment such as the Mobile Studio Boards. The department usually accepts between 200 and 300 first year student every year.

The current and future enrollment figures indicate that there is a significant pressure on the ECE departments of AAiT and iOTech-HU because they currently don't have the necessary funds to expand their laboratory equipment based on the student enrollment. Since the typical ECE department laboratory station (bench set-up) costs around \$5,000 USD, which is equivalent to $\$ 90,000$ Ethiopian Birr Currency (ETB), each department will need around $\$ 50,000$ USD (\$0.9M ETB) to $\$ 100,000$ USD (\$1.8M ETB) to put together a new laboratory with 10 to 20 working stations. The shortage of laboratory equipment implies that the majority of the ECE students enrolled at the two universities will not get the chance to acquire an extensive "handson" experience in their major courses before they graduate. One possible solution is to use a cost effective laboratory solution such as the MS-IOBoard. A basic configuration will cost around $\$ 500$, which is equivalent to one-tenth the cost of a typical ECE laboratory bench set-up. It will include the MS-IOBoard (\$150) [5], or the new Analog Discovery ${ }^{\mathrm{TM}}$ board (\$150) [6], a netbook/laptop (\$250) and miscellaneous tools and components (\$100). The addition of the portable equipment will allow the ECE departments of AAiT and iOTech-HU to offer various types of laboratory and hand-on projects to its students both inside and outside of its laboratories. Junior and Senior ECE students will be able to check out the systems to work on their course 
projects or final year senior projects, while the sophomore and junior students will be using the systems in their regular laboratory courses.

\section{The Mobile Studio Technology ${ }^{\mathrm{TM}}$ and Pedagogy}

The Mobile Studio Project, funded and supported by the National Science Foundation (NSF) has developed and is continuing to develop pedagogy and supporting hardware and software which, when connected to a PC (via USB), provides functionality similar to that of standard laboratory equipment (oscilloscope, function generator, power supplies, voltmeters, etc.) typically associated with a highly instrumented studio classroom or lab [5]. The MSIOBoard is a small, inexpensive hardware platform for use in a home, classroom or remote environment. When coupled with the Mobile Studio Desktop software, the system duplicates a large amount of the hardware valued at around $\$ 5,000$ (see Fig. 2). Specifically, the Mobile Studio pedagogy promotes nontraditional education as its focus is on student-centered experimentation anytime, anywhere utilizing hands-on learning to support more comprehensive, long-term knowledge retention of engineering concepts in a "real world" approach. The project's major goal is to enable hands-on exploration of ECE and other STEM education principles, devices, and systems that have historically been restricted to expensive laboratory facilities. The Mobile Studio has been used to teach courses in electrical engineering, computer engineering, and general engineering electronics; physics courses; and high school technology-oriented courses. It has been used extensively at RPI, MSU, Howard University and Rose-Hulman Institute of Technology, and Boston University[7][8]. It has also been used by the ECE department of MSU to offer several ECE courses online [9][10], and establish the first completely online undergraduate ECE program in the state of Maryland [11],[12].

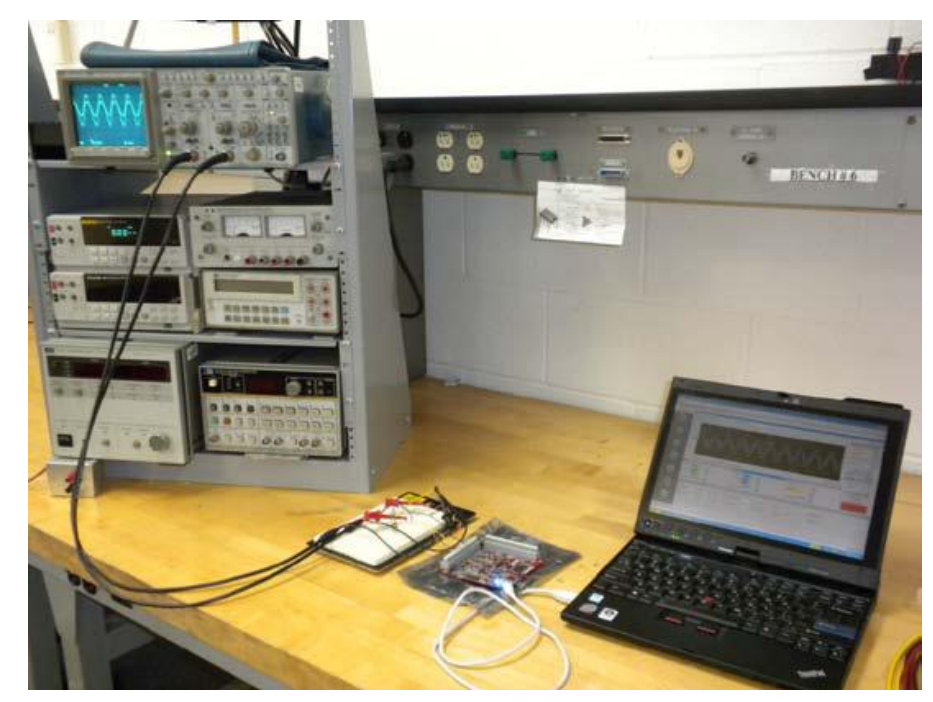

Figure 2: Mobile Studio Technology versus regular lab equipment 
A generic experimental configuration for a Mobile Studio based activity is shown in Fig. 3. The laptop, USB cable and Mobile Studio I/O Board ${ }^{\mathrm{TM}}$ and Desktop software provide the necessary measurement capabilities usually provided by an oscilloscope. The Mobile Studio Desktop software is used to store any data to a useful file format for spreadsheet or other analysis tools. It should be noted that the Mobile Studio hardware and software have been discontinued and are now replaced by the "Analog Discovery ${ }^{\mathrm{TM}}$ " board and associated software.

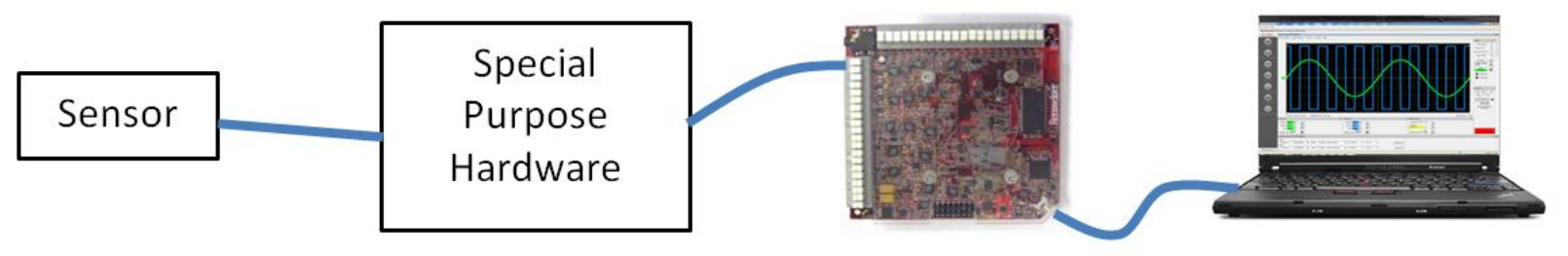

Figure 3: Mobile Studio Technology Set-up

\section{Impact of new technology and pedagogy}

Faculty at $\square$ have been testing the effectiveness of the MS-IOBoard technology in the ECE departments of AAiT and iOTech-HU since 2009 with the donation of 20 MS-IOBoards from the O'Sullivan foundation to expand the use of the new technology in two universities in Ethiopia. The ECE department at AAiT used the new equipment to allow its senior $\left(5^{\text {th }}\right.$ year $)$ students to work on their capstone design projects in groups of 3 to 5 students. The students indicated that the availability of the new technology allowed them to expand the application of their projects and tackle more advanced topics. Some of the special features of the MS-IOBoard that were exploited by the students are listed below. It should be noted that most of the features of the MS-IOBoard listed below that were exploited by the students are not available using other equipment in the ECE laboratories.

- Clamp activated Switch Project: the students used the spectrum analyzer function of the MSIOBoard to analyze the clap waveforms picked up by an electrets microphone. It allowed them to observe the sampled audio input from the microphone and analyze its general properties in the frequency domain. They were able to correctly determine the frequency range where the clap waveforms were concentrated, and were able to design a band pass filter that minimized false triggering of the circuit (see Fig 4). 

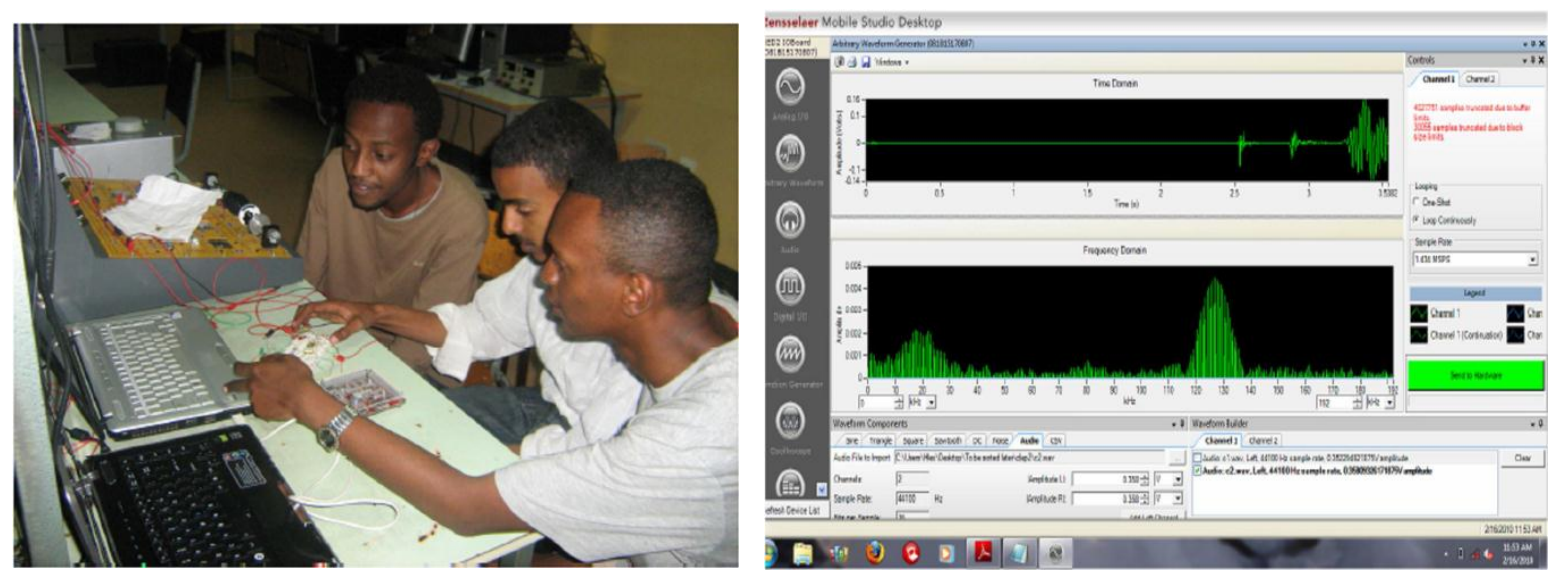

Figure 4: AAiT students working on their Clamp Activated Switch Project (left side). Spectrum Analyzer function of MS-IOBoard showing sound signal in the frequency domain (right side).

- Induction Machine Test Project : the students needed equipment that can supply signals with specific phase differences to test a phase detection circuit they designed. The main problem was that the conventional function generators that are available in their laboratory couldn't provide waveforms with the desired phase. Hence, testing circuits with a specific phase difference between two input waveforms was impossible. They used MS-IOBoard to simultaneously generate two signals with the desired phase difference and accurately test the performance of their phase detection circuit (see Fig 5).
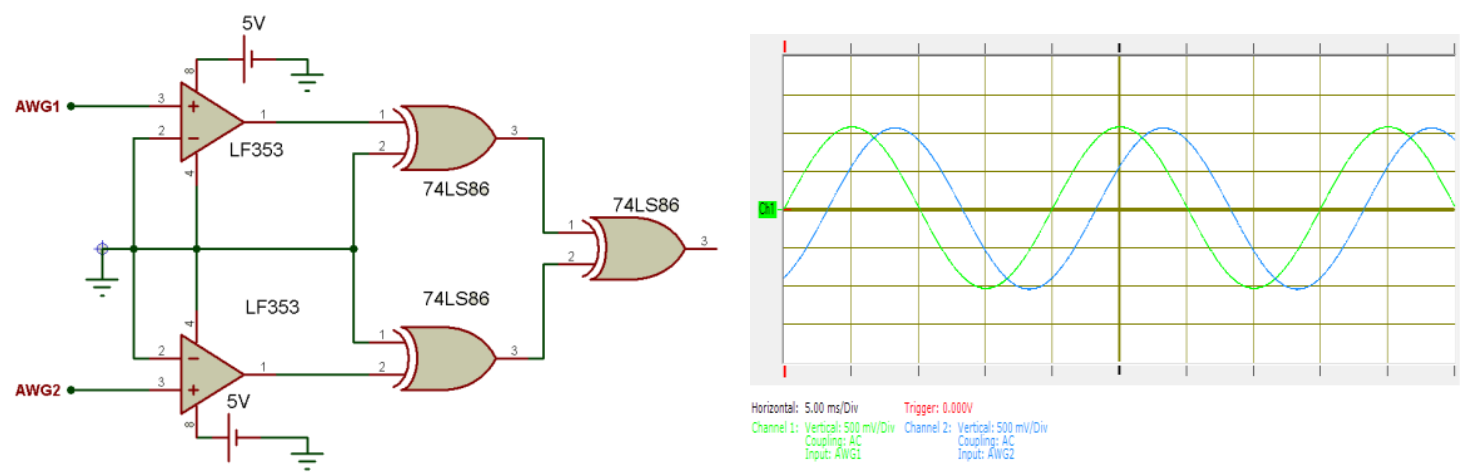

Figure 5: Phase detection circuit designed by AAiT students (left side). The MS-IOBoard software showing two signals with different phase shifts (right side).

- Vector-Cardiographic (VCG) Imaging System Project: this project demonstrated the best application of the MS-IOBoard. Their project consisted of designing a system for displaying the vector-cardiogram (VCG) of a human heart. The main problem was that they only had access to very poor quality metallic electrodes that prevented them from picking good Electroccrdiography (ECG) signals from the skin of a human being. The students came up with a clever solution using the MS-IOBoard. They first downloaded ECG recordings of a real patient from a medical database (www.physionet.org). They then wrote a small script to convert the recordings to a CSV format and use the MSBoard software to process the data. This implied that the two lead ECG signals, which would have been acquired through the electrodes, were simulated by sending two synchronized clinically pre-recorded ECG signals through the two output ports of the MSBoard called AWG1 and AWG2. Since the output of 
the mobile studio resembles the output of an ECG instrumentation amplifier, they connected them to two different microcontrollers. This allowed them to validate the microcontroller logic outputs independent of the functionality of sensors and instrumentation amplifiers (see Fig 6).
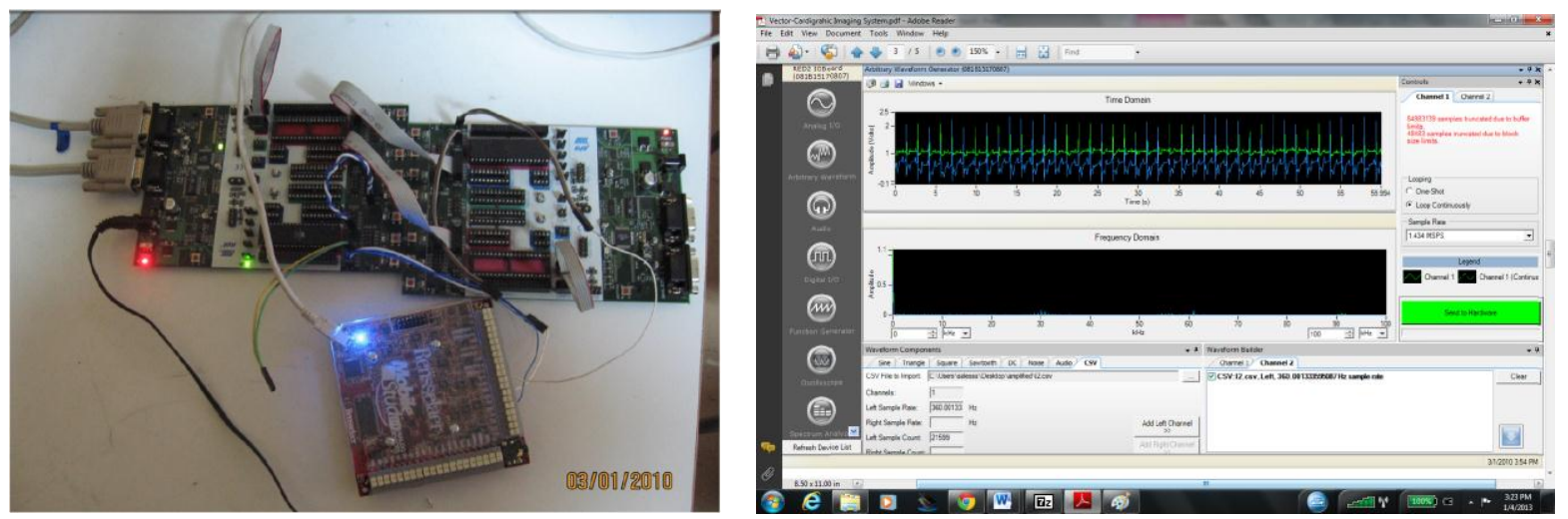

Figure 6: Mobile Studio set-up for VCG Imaging project (left side). ECG Signal captured inside MS-IOBoard Software (right side).

The ECE department of iOTech-HU used the MS-IOBoards to expand the laboratory equipment used in sophomore and junior level courses. The pictures shown in Fig. 7 indicate the MSU faculty donating the MS-IOBoards to the chair of the ECE department. The picture in Fig 7 (right side) shows a typical ECE laboratory set-up at iOTech-HU. One can clearly notice the lack of instrumentation. Prior to the availability of the MS-IOBoards, students were forced to work in groups of 10 to 20 students to conduct basic ECE laboratory experiments (see Fig 8: left side). The addition of 10 new MS-IOBoards allowed the ECE department to triple its laboratory workstation benches and allow fewer (4 to 5) students per station to conduct their laboratory experiments (see Fig 8: right side).
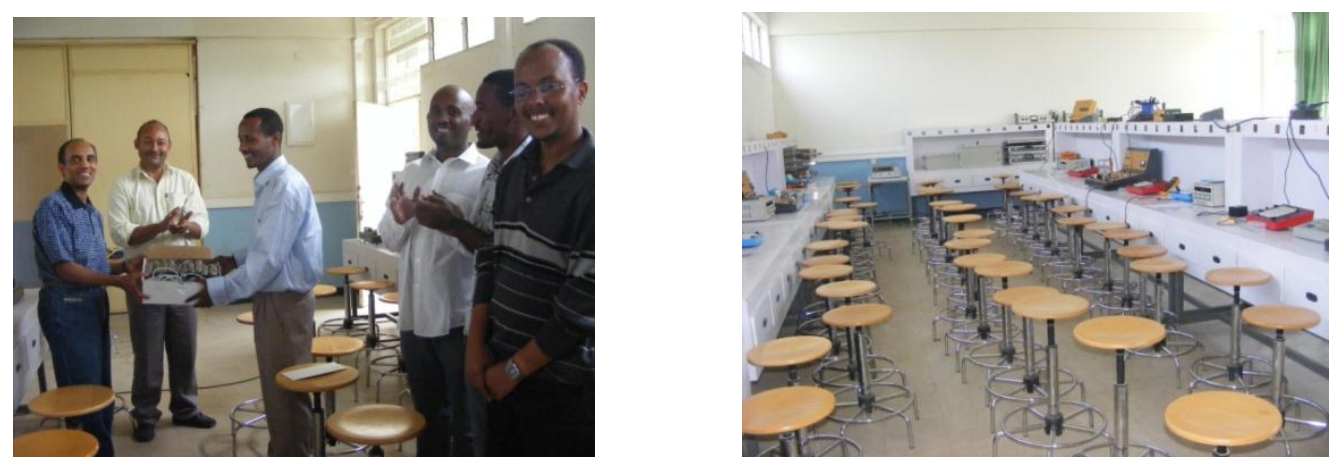

Figure 7: Delivering the Mobile Studio boards to ECE department chair and staff (left side). Typical ECE laboratory at iOTech-HU (right side). 

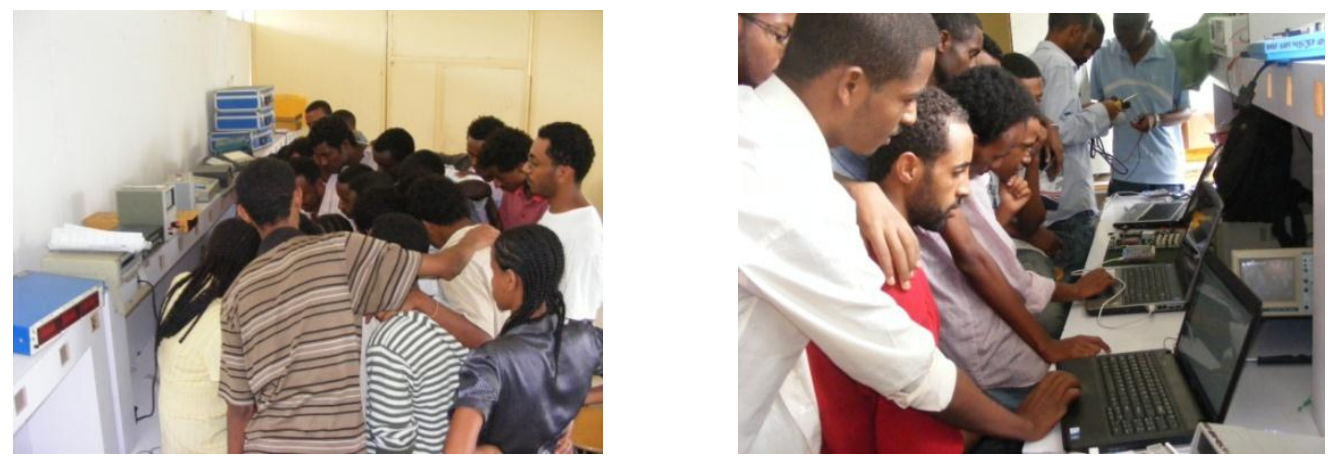

Figure 8: Typical ECE Lab session before implementation of new instrumentation and pedagogy (left side). ECE Lab session after implementation of new MS-IOBoard instrumentation and pedagogy (right side).

\section{Conclusion and future work}

The implementation of the MS-IOBoard technology and pedagogy has greatly enhanced and improved the learning experience of ECE students enrolled at AAiT and iOTech-HU. Some students have gone beyond using the basic functionalities of the MS-IOBoard. Senior students at AAiT explored and discovered the various advanced features of the mobile studio boards on their own. One group actually took the use of the MS-IOBoard even further by developing and testing a new feature that was not available with the mobile studio software. They implemented a new "Bode Plotter" function for the MS-IOBoard using the Matlab software that allows users to plot the frequency response of circuits without the need of a new hardware. The MS-IOBoard technology has proven to be very dependable and reliable during the past three years with only two of the original boards requiring repair or replacement. The MS-IOBoard technology has now been replaced by a new and improved Analog Discovery ${ }^{\mathrm{TM}}$ board, built by Digilent Inc. At a cost of $\$ 99$ per unit, the new boards will allow ECE departments throughout Africa to start teaching laboratory courses at a fraction of the cost of purchasing regular laboratory equipment. The new Analog Discovery ${ }^{\mathrm{TM}}$ website [6] has additional instructions, lessons, videos, and other very helpful documents that can be accessed freely by anyone interested in teaching ECE laboratory courses.

has continued its support and collaboration with ECE departments at AAiT and iOTech-HU. The demand from other universities has been so high that we organized a short two day conference in May 24-25, 2012 and provided workshops on engineering education and training on the use of the MS-IOBoard to three additional universities in Ethiopia. The conference was organized using funding from Analog Devices Inc (ADI), and Innovative STEM Solutions Inc (ISTEMS). ADI donated: 40 MS-IOBoards, 15 laptops, and other laboratory accessories for universities in Ethiopia. ISTEMS provided the transportation and shipping of the donations to Ethiopia. The workshops attracted 15 faculty members and administrators from five universities. The goals of the workshops were to give the participants important information and 
hands-on practice related to effective teaching, such as: course planning, effective lecturing, active learning, and assessment of learning. Finally, the workshops were also intended to provide new and experienced faculty members with instructional materials and teaching methods that they can use and share with other faculty members on their own campuses. We will present the results of the new collaborations in future conferences.

\section{References}

[1] International Organization for Migration (IOM): http://www.iom.int/cms/en/sites/iom/home.html

[2] Canada's International Development Research Center (IDRC): http://www.idrc.ca/EN/AboutUs/Pages/default.aspx

[3] N.V. Varghese, "Growth and Expansion of Private Higher Education in Africa", UNESCO report, Paris, France, 2006.

[4] Ethiopian University Capacity Building Program (ECBP): http://www.giz.de/themen/en/16850.htm

[5] The Mobile Studio Project: https://sites.google.com/a/mobilestudioproject.com/mobilestudio-project/

[6] Digilent Inc's, Analog Discovery ${ }^{\mathrm{TM}}$ : http://www.digilentinc.com/eeboard/

[7] D. Millard, M. Chouikha, and F. Berry, "Improving Student Intuition via Rensselaer s New Mobile Studio Pedagogy", ASEE 2007 Annual Conference, Honolulu, HW, June 2007.

[8] K. Conner, et. al., "Multi-Institutional Development of Mobile Studio Based Education and Outreach," 2011 American Society of Engineering Education (ASEE) Annual Conference, Vancouver, British Columbia, Canada, June 26-29, 2011.

[9] Yacob Astatke, Jumoke Ladeji-Osias, Craig Scott, “Online Delivery of Electrical Engineering Laboratory courses," Proceedings of 2012 American Society of Engineering Education (ASEE) Annual Conference, San Antonio, Texas, June 10-13, 2012.

[10] Y. Astatke, J. Ladeji-Osias, C. J. Scott, K. Abimbola, and K. Conner, "Developing and Teaching Sophomore Level Electrical Engineering Courses Completely Online”, Journal of Online Engineering Education, 2(2) 2011.

[11] Y. Astatke, C. Scott, J. Ladeji-Osias, "Electric Circuits Online- Towards a completely Online Electrical Engineering Curriculum," 2011 American Society of Engineering

Education (ASEE) Annual Conference, Vancouver, British Columbia, Canada, June 26-29, 2011.

[12] Craig Scott, Yacob Astatke, Jumoke Ladeji-Osias, "Innovative Strategies for Implementing an Online Undergraduate Electrical Engineering Program, ” Proceedings of 
2012 American Society of Engineering Education (ASEE)Annual Conference, San Antonio, Texas, June 10-13, 2012.

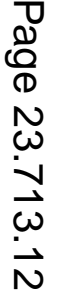

